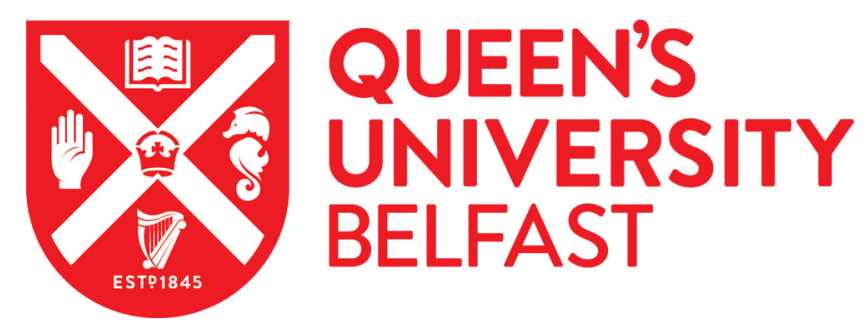

\title{
Mindfulness as a Well-being Initiative for Future Nurses: A Survey With Undergraduate Nursing Students
}

McVeigh, C., Reid, J., Carswell, C., Ace, L., Walsh, I., Graham-Wisener, L., Rej, S., Potes, A., Atkinson, K., Edginton, T., \& Noble, H. (2021). Mindfulness as a Well-being Initiative for Future Nurses: A Survey With Undergraduate Nursing Students. BMC Nursing, 20, [253]. https://doi.org/10.1186/s12912-021-00783-0

\section{Published in:}

BMC Nursing

Document Version:

Publisher's PDF, also known as Version of record

Queen's University Belfast - Research Portal:

Link to publication record in Queen's University Belfast Research Portal

\section{Publisher rights}

Copyright 2021 the authors.

This is an open access article published under a Creative Commons Attribution License (https://creativecommons.org/licenses/by/4.0/), which permits unrestricted use, distribution and reproduction in any medium, provided the author and source are cited.

\section{General rights}

Copyright for the publications made accessible via the Queen's University Belfast Research Portal is retained by the author(s) and / or other copyright owners and it is a condition of accessing these publications that users recognise and abide by the legal requirements associated with these rights.

Take down policy

The Research Portal is Queen's institutional repository that provides access to Queen's research output. Every effort has been made to ensure that content in the Research Portal does not infringe any person's rights, or applicable UK laws. If you discover content in the Research Portal that you believe breaches copyright or violates any law, please contact openaccess@qub.ac.uk. 


\title{
Mindfulness as a well-being initiative for future nurses: a survey with undergraduate nursing students
}

\author{
Clare Mc Veigh $^{1 *}$ DD, Joanne Reid ${ }^{1}$, Claire Carswell ${ }^{1}$, Lindsay Ace ${ }^{1}$, lan Walsh², Lisa Graham-Wisener ${ }^{3}$, Soham Rej ${ }^{4,5}$,
} Angela Potes ${ }^{5}$, Karen Atkinson ${ }^{6}$, Trudi Edginton ${ }^{7}$ and Helen Noble ${ }^{1}$

\begin{abstract}
Background: Mindfulness can potentially positively impact well-being and resilience in undergraduate nursing students. The psychological well-being of such students undertaking clinical training is paramount to ensure optimal learning, and to equip them with skills to manage their wellbeing in future clinical practice. The aim of our study was to explore the views of undergraduate nursing students in relation to understanding and engaging with mindfulness, and how mindfulness could best be delivered within their university programme.

Methods: An online survey was administered via a cloud-based student response system to a convenience sample of first year undergraduate nursing students completing a Bachelor of Science (BSc) Honours (Hons) degree in nursing at a University in the United Kingdom. Data were analysed using descriptive statistics and thematic analysis.

Results: The survey achieved a response rate of $78 \%(n=208)$. Seventy-nine percent of participants had heard of mindfulness and were interested in taking part in a mindfulness programme. Respondents reported that the ideal delivery of the programme would consist of weekly 45-min, in person group sessions, over a 6-week period. Respondents also indicated that a mobile application could potentially facilitate participation in the programme. Thematic analysis of open-ended comments, and free text, within the survey indicated 4 overarching themes: 1) Perceptions of what mindfulness is; 2) Previous mindfulness practice experiences; 3) Impact of mindfulness in nursing; 4) The need for a future well-being initiative for undergraduate nursing students.

Conclusions: Undergraduate nursing students perceived that a mindfulness programme has the potential to enhance well-being and future clinical practice. This student cohort are familiar with mindfulness and want more integrated within their undergraduate curriculum. Further research is required to examine the effectiveness of a tailored mindfulness intervention for this population that incorporates the use of both face-to-face and mobile delivery.
\end{abstract}

Keywords: Indfulness, Nursing students, Undergraduate, Healthcare, Meditation

\section{Background}

Psychological morbidity is recognised as a growing global concern amongst nursing students [1,2]. Evidence suggests that the nature of healthcare education can contribute to the high levels of psychological morbidity amongst

\footnotetext{
* Correspondence: clare.mcveigh@qub.ac.uk

'School of Nursing and Midwifery, Queen's University Belfast, Belfast, UK Full list of author information is available at the end of the article
}

health service students [3-5], with clinical placements being identified as a particular stress trigger [6]. It is internationally recognised that engaging in mindfulness can positively impact the holistic wellbeing and resilience of nursing and medical students [7-9]. Enhanced psychological well-being of students undertaking clinical training is essential to ensure optimal learning, and also to prepare them for future healthcare challenges [10]. Mindfulness

C C The Author(s). 2021 Open Access This article is licensed under a Creative Commons Attribution 4.0 International License, which permits use, sharing, adaptation, distribution and reproduction in any medium or format, as long as you give appropriate credit to the original author(s) and the source, provide a link to the Creative Commons licence, and indicate if changes were made. The images or other third party material in this article are included in the article's Creative Commons licence, unless indicated otherwise in a credit line to the material. If material is not included in the article's Creative Commons licence and your intended use is not permitted by statutory regulation or exceeds the permitted use, you will need to obtain permission directly from the copyright holder. To view a copy of this licence, visit http://creativecommons.org/licenses/by/4.0/ The Creative Commons Public Domain Dedication waiver (http://creativecommons.org/publicdomain/zero/1.0/) applies to the data made available in this article, unless otherwise stated in a credit line to the data. 
has the potential to fit well within a continuum of best practice in healthcare [11].

Mindfulness has been described as being able to have present-moment awareness, in a non-judgemental manner and without criticism [12]. Mindfulness may be obtained through purposively focusing fully on present experiences [13], thus providing a simplistic platform by which participants can enhance their own well-being [14]. However, formal mindful practices (e.g. breath awareness, body scans) can enhance the capacity for present-moment awareness and acceptance/non-judgment [15]. When utilising mindfulness, improvements may be experienced in relation to attention $[16,17]$, well-being $[18,19]$ and resilience $[20,21]$ in both clinical and non-clinical populations. Resilience is a trait that can help people cope with adversity, trauma and difficult events. It is an ineffable quality which allows individuals to cope effectively with failure; often supported by a positive and optimistic attitude. Within the healthcare profession, resilience plays a key role in enhancing the quality of care delivered to patients and workforce sustainability [22]. In India, a cross sectional survey of undergraduate medical students $(n=353)$ reported that psychological symptoms such as depression (51.3\%), anxiety (66.9\%) and stress (53\%) were experienced by over half of participants [23].

Participating in mindfulness interventions can increase well-being amongst nursing students [9] by reducing symptoms such as anxiety and stress. It has previously been highlighted that nurses can experience higher levels of stress-related burnout, in comparison with other health care professionals [24]. Burnout within the workplace can have a negative impact on the biopsychosocial well-being of nursing staff, as well as impacting patient care, and career satisfaction [25]. Additionally, stress and burnout can lead to higher staff turnover amongst registered nurses [26] and newly qualified nurses [27]. An Australian study exploring the implementation of a 7-week mindfulness program, delivered using an audio $\mathrm{CD}$, for nursing and midwifery students reported an increase in general well-being, and enhanced clarity of thought amongst this population [28]. In China, a face-to-face mindfulness intervention had a positive impact on nursing students' physiological health through lowering blood pressure [29]. Amongst medical students, mindfulness not only decreased perceived levels of stress but also increased self-compassion [30]. However, due to academic and clinical demands nursing students may not avail of traditional face-to-face mindfulness interventions [14].

Alongside the growing recognition of mindfulness practices, there is an increasing awareness that mindful meditation interventions need to be more accessible to participants [31]. One way in which mindfulness programs can be more readily accessed is through the use of online technology. Amongst newly qualified registered nurses, previous research highlighted that a mindfulness intervention delivered online reduced anxiety [32]. However, the most effective delivery of mindfulness interventions in helping to promote well-being and resilience amongst nursing students is unclear. The aim of our study was to identify the views of undergraduate nursing students in relation to mindfulness, and how it could be embedded within their university curriculum.

\section{Method \\ Design}

A cross-sectional online survey was administered via a cloud-based student response system that students could access via their computer or handheld mobile device, to identify participants' perceptions and experiences in relation to mindfulness meditation and its implementation.

\section{Setting}

This survey involved first year undergraduate nursing students enrolled on the BSc (Hons) Nursing programme at a University in Northern Ireland. A mindfulness initiative is not currently available to this student cohort.

\section{Sample and participants}

A convenience sample of undergraduate nursing students completing a BSc Hons Degree in Nursing were approached. All participants were in the first year of the nursing programme and had completed two clinical placements. This sample was chosen as students had both experience of clinical placement and the university setting, and the sample was readily accessible to the researcher [33]. Participants were provided with details about the study prior to the survey being administered. Consent to participate in the study was implied by completion and submission of the survey via the cloud-based platform.

\section{Ethical considerations}

The study received ethics approval from the Queen's University Belfast, School of Nursing and Midwifery Research and Ethics Committee (Ref: C.McVeigh.05.19.M1.V1).

\section{Instrument}

The 21-item survey (Table 1) was developed by the authors based on previous pilot research [8], and a review of the literature $[1-11,28,29]$. It consisted of demographic questions $(n=3)$, multiple-choice items $(n=8)$ and open-ended questions $(n=5)$. Questions focused on participants understanding of mindfulness, their past and present engagement with mindfulness practice, and their views on how a mindfulness programme could be integrated into the undergraduate nursing curriculum. 


\section{Table 1 Survey}

1. Have you heard of mindfulness? YES/ NO

If No, please go directly to question 8.

2. What is your understanding of Mindfulness?

3. Have you engaged in mindfulness practice? YES/ NO

4. If you answered YES to question 3, please describe the mindfulness practice you engaged in.

5. If you have engaged in mindfulness practice, did it help you and how?

6. Do you practice any other meditation/ mind-body practices (e.g. yoga, tai (chi)?

YES/ NO

7. If you answered YES to question 6, how often do you practice each week?

8. Would you be interested in taking part in a new mindfulness programme with other nursing students?

YES/ NO

9. How long do you think a weekly group mindfulness session should be?

A. $45 \mathrm{~min}$

B. $60 \mathrm{~min}$

C. $90 \mathrm{~min}$

D. $2 \mathrm{~h}$

E. Other

10. If you chose OTHER, please explain.

11. How many weeks long should the mindfulness programme be?

A. 4 weeks

B. 5 weeks

C. 6 weeks

D. 8 weeks

E. Other

12. If you chose OTHER, please explain.

13. In addition to the group mindfulness programme, would you be happy to do personal mindfulness practice in your own time? YES/NO

14. Do you think a student well-being initiative should be part of the nursing curriculum?

15. How do you think mindfulness practice may benefit you as a nurse in clinical practice?

16. Are there any barriers that might prevent you from participating in mindfulness practice?

17. Which of the following do you think may help to facilitate your participation in mindfulness practice?

PLEASE SELECT ALL THAT APPLY

A. Student champion

B. A Mobile APP

C. Student-led lunchtime meditation sessions

D. Other

18. If you chose OTHER please explain.

19. What is your age group?

A. $18-22$ years

B. 23-30 years

C. $31-40$ years

D. $41-50$ years

E. $50+$ years

20. What is your gender?

A. Male

B. Female
Table 1 Survey (Continued)

\author{
C. Other \\ 21. What is your Ethnic Group? \\ A. White British \\ B. White Irish \\ C. Irish Traveller \\ D. Any other White Background \\ E. White and Black Caribbean \\ F. White and Black African \\ G. White and Asian \\ H. Any other Mixed/ Multiple Ethnic Background \\ I. Indian \\ J. Pakistani \\ K. Bangladeshi \\ L. Chinese \\ M. Any other Asian Background \\ N. African \\ O. Caribbean \\ P. Any other Black Background
}

\section{Data collection}

The questionnaire took approximately 10 to $15 \mathrm{~min}$ to administer and complete. Participants were approached at the beginning of a lecture and asked to participate anonymously using the cloud-based student response system that they had been using previously in class. The study was conducted in May 2019.

\section{Analysis}

Closed response survey data were entered into SPSS version 24 [34] and descriptive statistics were used to summarise the data. Free text responses were analysed by the lead author (CMV) using thematic analysis [35] to identify overarching themes that emerged from the data. Themes were then reviewed by other members of the research team (JR, CC, IW, LGW, SR, AP, KA, TE, HN). Stage one of analysis involved assigning descriptive themes to sections of the data, whilst stage two encompassed grouping together these descriptive themes to generate interpretative themes that highlighted emerging patterns within the data [36]. The final stage identified a number of overarching themes that were developed by pulling together and linking all the interpretative themes.

\section{Results}

Two hundred and sixty-six students were approached to participate in the study, and from those 208 consented giving a response rate of $78 \%$. Demographic details are presented in Table 2 . Amongst respondents, the majority were between the ages of $18-22$ years $(51.9 \%)$, female (84.6\%) and white Irish or British (83.6\%). Closed response survey data is presented in Table 3.

The majority of respondents had heard of mindfulness (76.4\%), and $37 \%$ had engaged in a mindfulness practice. Additionally, $17.8 \%$ of respondents reported that they had engaged in other meditation/mind-body practices. 
Table 2 Demographic characteristics

\begin{tabular}{ll}
\hline Sex & $\boldsymbol{N}(\%)$ \\
\hline Female & $176(84.6 \%)$ \\
Male & $10(4.8 \%)$ \\
Question not answered by participants & 0 \\
Age & $22(10.6 \%)$ \\
18-22 years & \\
23-30 years & $108(51.9 \%)$ \\
31-40 years & $45(21.6 \%)$ \\
41-50 years & $30(14.4 \%)$ \\
50 years + & $3(1.5 \%)$ \\
Question not answered by participants & 0 \\
Ethnic Group & $22(10.6 \%)$ \\
White Irish or British & \\
African & $174(83.6 \%)$ \\
Any other Asian background & $1(0.5 \%)$ \\
Any other Mixed/Multiple ethnic background & $1(0.5 \%)$ \\
Any other White background & $2(1 . \%)$ \\
White and Black African & $4(1.9 \%)$ \\
Question not answered by participants & $1(0.5 \%)$ \\
\hline
\end{tabular}

The majority of respondents (67.8\%) reported that they would be interested in taking part in a mindfulness programme with other nursing students. A chi-square statistic was calculated to examine any association between participants who had heard of mindfulness and those who would be interested in taking part in a new programme, but there was no significant association $(p>0.05)$. When asked about the preferred length of a weekly mindfulness sessions the majority of respondents (55.8\%)reported $45 \mathrm{~min}$ as their preferred length of time. With regards to the length of the mindfulness programme itself, the majority of students (38.9\%) indicated that 6 weeks was the ideal length of time in which to deliver the full programme. In addition, over three quarters of nursing students (77.9\%) reported that they would be happy to engage in personal mindfulness practice in their own time, alongside the mindfulness programme. This was not significantly associated $(p=0.476)$ with whether these nursing students had heard of mindfulness before. Interestingly, $71.6 \%$ of respondents indicated that a mobile application could potentially help facilitate their participation in a mindfulness programme. Others indicated that lunchtime meditation sessions (20.7\%) or a student champion (13\%) may help enhance participation in the programme.

Thematic analysis of the open-ended responses generated 4 overarching themes (Table 4): Perceptions of what mindfulness is; Previous mindfulness practice experiences; Impact of mindfulness in nursing; The need for a future well-being initiative for undergraduate nursing students.
Table 3 Closed response survey data

\begin{tabular}{ll}
\hline Question & $\boldsymbol{N}(\%)$ \\
\hline $\begin{array}{l}\text { Have you heard of mindfulness? } \\
\text { Yes }\end{array}$ & $159(76.4 \%)$ \\
No & $43(20.7 \%)$ \\
Not answered & $6(2.9 \%)$ \\
Have you engaged in mindfulness practice? & \\
Yes & $77(37 \%)$ \\
No & $84(40.4 \%)$ \\
Not answered & $47(22.6 \%)$
\end{tabular}

Do you practice any other meditation/mind-body practices (e.g. yoga, tai chi)?

$\begin{array}{ll}\text { Yes } & 37(17.8 \%) \\ \text { No } & 157(75.5 \%) \\ \text { Not answered } & 14(6.7 \%)\end{array}$

Would you be interested in taking part in a new mindfulness programme with other nursing students?

$\begin{array}{ll}\text { Yes } & 141(67.8 \%) \\ \text { No } & 55(26.4 \%) \\ \text { Not answered } & 12(5.8 \%)\end{array}$

How long do you think a weekly group mindfulness session should be?

$\begin{array}{ll}45 \mathrm{~min} & 116(55.8 \%) \\ \mathbf{6 0} \mathrm{min} & 47(22.6 \%) \\ 90 \mathrm{~min} & 2(1 . \%) \\ 2 \mathrm{~h} & 1(0.5 \%) \\ \text { Other } & 14(6.7 \%) \\ \text { Not answered } & 28(13.4 \%)\end{array}$

How many weeks long should the mindfulness programme be?

$\begin{array}{ll}4 \text { weeks }(36.7 \%) & 66(31.8 \%) \\ 5 \text { weeks }(4.4 \%) & 8(3.9 \%) \\ 6 \text { weeks }(45 \%) & 81(38.9 \%) \\ 8 \text { weeks }(6.1 \%) & 11(5.3 \%) \\ \text { Other }(7.8 \%) & 14(6.6 \%) \\ \text { Not answered } & 28(13.5)\end{array}$

In addition to the group mindfulness programme, would you be happy to do personal mindfulness practice in your own time?

$\begin{array}{ll}\text { Yes } & 162(77.9 \%) \\ \text { No } & 30(14.4 \%) \\ \text { Not answered } & 16(7.7 \%)\end{array}$

Which of the following do you think may help to facilitate your participation in mindfulness practice?

Please select all that apply.

Student Champion $27(13 \%)$

A Mobile APP $\quad 149(71.6 \%)$

Student Led Lunchtime Meditation Sessions $\quad 43$ (20.7\%)

Other $14(6.7 \%)$

Not answered $\quad 26(12.5 \%)$

The first overarching theme, perceptions of what mindfulness is, highlighted participants views of mindfulness as a strategy to promote self-care that could also enable 
Table 4 Thematic analysis of open-ended questions and free text comments

\section{Overarching Themes}

Perceptions of what mindfulness is

Previous Mindfulness Practice experiences

Impact of mindfulness in nursing

The need for a future well-being initiative for undergraduate nursing students
Mindfulness is about self-care

Being mindful of others

Enhanced awareness

Helped to relax

Enhanced mental well-being

Previous mindfulness practice not beneficial

Benefits to students undertaking the undergraduate nursing programme

Benefits to future clinical practice

Barriers to mindfulness in undergraduate nursing programme

Nursing course is stressful

Student forgotten

\section{Participant quotes}

Mindfulness is about inner peace and looking after your mental health

Mindfulness is a way of unwinding and going to a better place

Mindfulness is to reduce stress

You have to look after yourself to look after others

I think mindfulness means to be open without judgement. To be empathetic towards others and how your words and actions can help or hinder others

Mindfulness is being aware of your thoughts and feelings in response to external influencing factors

Being aware of what is going on at the present moment, being present and not hooked up in the past or future

Taking time to be at peace with your thoughts and emotions

Mindfulness helped to relax my mind and provide peace

I loved meditation as it helped me focus on that moment on my breathing and sensations throughout my body, so I was distracted from everything else

Mindfulness does help before I go to sleep

Mindfulness alleviated stress and made me happier

Mindfulness removed some worrisome thoughts from my head, validated my feelings and allowed me time to focus on more important things

Mindfulness helped me to stop being so anxious and to stop worrying about the future so much

I didn't stick at mindfulness long enough to see any sort of development Mindfulness didn't help, it made me more stressed and I just didn't get it

I found mindfulness a waste of time

Help you to keep the stress of the nursing course and profession overall down, as it is a demanding full-time course, and if you don't practice mindfulness etc. your mental health could become worse due to these stresses

Mindfulness would be a good way to relieve stress and understand the thoughts that are going through your head as well as better equip students for life after university

Mindfulness will help me appreciate my skills and assure me that I am a good nurse

Mindfulness would allow me to recognise the signs of burnout and mental fatigue, both in myself and other people, and give me the right tools to help combat negative feelings

Mindfulness would help me to cope with the pressure of clinical practice and increase compassion and communication skills

I don't personally believe in mindfulness

The previous time I tried a mindfulness class actually stressed me out more as doing nothing made me feel lazy

Timing is a barrier of course. For example, if it would interfere with study for exams or completing assignments

Time constraints and stress

This course is very demanding and experiences on placement can have a major impact on nursing students

The pressure and workload of the course can become overwhelming especially around the end of the year. A well-being initiative would be useful to help student nurses cope with stress and learn how to balance university, placement and home commitments.

The course is often focussed solely on the patient therefore the professional, or even the student, I personally feel are not regarded. 
Table 4 Thematic analysis of open-ended questions and free text comments (Continued)

\begin{tabular}{ll}
\hline Overarching Themes & Participant quotes \\
\hline & $\begin{array}{l}\text { Sometimes the student's well-being can be forgotten about, it's important } \\
\text { that they are well in order to attend university and complete certain tasks } \\
\text { given to them. }\end{array}$ \\
$\begin{array}{ll}\text { Take care of the students so they } \\
\text { can take care of others }\end{array}$ & $\begin{array}{l}\text { Taking care of our [the student] health and wellbeing first and foremost so } \\
\text { we can help others } \\
\text { A well-being initiative would help teach future self-care methods for our } \\
\text { nursing career }\end{array}$ \\
Future well-being initiative should & $\begin{array}{l}\text { A future well-being initiative should be available but maybe not } \\
\text { mandatory }\end{array}$ \\
& $\begin{array}{l}\text { A well-being initiative could benefit some students, but it may not because } \\
\text { missing a session can lead to more stress. The curriculum is already full } \\
\text { time and it would be difficult to add more to it. }\end{array}$
\end{tabular}

them in being more mindful of others. Additionally, mindfulness was described as related to enhancing awareness of the present moment and of their thoughts. The overarching theme; previous mindfulness practice experiences, pertained to participants' perceptions of their previous mindfulness practice. Many participants felt it had helped them to relax and enhanced their mental well-being. However, some participants additionally indicated that previous mindfulness practice had not been beneficial to them due to factors such as; not practicing long enough to benefit from mindfulness, perceiving mindfulness to have increased their stress or finding the practice of no benefit. Overarching theme 3, impact of mindfulness in nursing, described how mindfulness could potentially benefit students undertaking the undergraduate nursing programme. It was also recognised that there might be barriers to student participation. Participants additionally highlighted that mindfulness had the potential to positively impact their future clinical practice. Within the need for a future well-being initiative for undergraduate nursing students (overarching theme 4), responses conveyed the perception amongst participants that due to the stressful nature of their nursing programme, a well-being initiative may be beneficial for students and aid in the student not being 'forgotten.' Perceptions highlighted that a future initiative should help enhance the well-being of students so they can optimally care for others. However, several participants conveyed the importance of future well-being initiatives as optional for nursing students and not a compulsory element of the curriculum.

\section{Discussion}

This study produced new knowledge in relation to undergraduate nursing students' perceptions of a mindfulness- based well-being initiative within the university curriculum. Previous research has indicated a lack of standardised approach to delivering a mindfulness programme to undergraduate nursing students [37].
Within the present study, participants indicated that the ideal delivery for a mindfulness programme would incorporate weekly 45-minute face-to-face sessions over a 6-week period. Participants in the present study expressed willingness to engage in their own mindfulness practice, alongside the mindfulness programme.

An additional finding of the present study indicated that the majority of undergraduate nursing students would prefer a mobile application to aid their participation in mindfulness meditation. Previous research exploring mindfulness practice delivered by a mobile application to medical students, highlighted decreased perceived stress and increased general well-being amongst participants [38].

A 12-week Mindfulness Based Stress Reduction (MBSR) programme for Turkish nursing students found increased awareness of staying in the present amongst participants [39]. Nursing students who participated in the present study perceived that mindfulness would enable them to enhance their awareness, but also encourage self-care. Data additionally demonstrated the potential impact of mindfulness on nursing practice at undergraduate level. Due to the demanding nature of their course, nursing students believed mindfulness could potentially help build coping strategies to deal with stress. Those who had engaged in previous practice conveyed that it had aided relaxation and enhanced their mental well-being through alleviating stress or anxiety. Previous research has similarly demonstrated perceived reduction in stress and anxiety amongst nursing students who engaged in MBSR [9, 32, 40, 41]. Engaging in mindfulness practice has also been shown to improve quality of life amongst both undergraduate nursing students, and registered nurses [42].

The benefits of mindfulness have not only been recognised amongst undergraduate nursing students, but also registered nurses working in clinical settings. Previous research involving newly registered nurses $(n=5)$ in Canada investigated the effectiveness of a shortened 
version of the 8-week Mindfulness Based Stress Reduction (MBSR) course [43]. The shortened MBSR programme aided participants in recognising their stress levels, increasing their self-compassion and recognising their capabilities and limitations in clinical practice. Similarly. within the present study participants expressed that participating in a mindfulness programme might aid them in recognising personal signs of burnout and mental fatigue which could enhance coping strategies when practicing as a registered nurse. In addition, participants felt that mindfulness practice could increase compassion and improve clinical practice if they were aware of how well they were doing their job. Previous pilot research by the current authors [8] found that a 6-week mindfulness course could increase mindfulness and resilience amongst both nursing and medical students. Mindfulness has the potential to enhance resilience amongst future nurses working in clinical practice.

Within the present study some participants who had previously engaged in mindfulness practice felt it was unhelpful and even exacerbated their stress. Some additionally expressed that a mindfulness programme would not be feasible within the current undergraduate nursing curriculum due to time constraints and the busy nature of the programme. Previous research with trainee social workers recommended that mindfulness may not appeal to all students and therefore should not be mandatory [43]. Another study highlighted that a 7-week MBSR course delivered as a compulsory element to first year undergraduate medical students, had lower levels of satisfaction and feedback compared to an optional course for 2nd year medical students [44]. The present study additionally highlighted that this is the perception in relation to well-being initiatives in general, and not just mindfulness-based interventions. However, the majority of UG nursing students recognised the need for a noncompulsory well-being strategy within the undergraduate nursing curriculum, for clinical practice and promote self-care.

\section{Limitations and future research}

This study included a convenience sample of participants from one university and therefore results may not be generalisable. In addition, the survey instrument was developed specifically for this study with no psychometric testing. However, the survey was designed by the authors based on previous pilot research and a review of the literature. With regard to future research, an extension of this study is recommended adopting the Medical Research Council (MRC) framework for complex interventions [45] to develop a mindfulness meditation programme for UG nursing students. This would initially involve conducting a feasibility study with undergraduate nursing students to explore the practicalities of implementing the proposed programme. This would be followed by an interventional study to determine the effectiveness of the programme on a number of outcomes This stage would focus on testing the intervention based on the data obtained from the feasibility study.

\section{Conclusions}

In conclusion, findings from the survey suggested that implementation of a mindfulness meditation programme would be acceptable to undergraduate nursing students. The results of this study provide important insights regarding how this programme may be optimally delivered using face-to-face sessions, and a mobile platform. The importance of ensuring that a well-being initiative is not a mandatory element of the undergraduate nursing curriculum has also been highlighted. Further research is needed to explore the feasibility of implementing a blended approach mindfulness programme for undergraduate nursing students.

\section{Abbreviations}

BSc: Bachelor of Science; Hons: Honours; MBSR: Mindfulness-Based Stress Reduction

\section{Acknowledgments}

The authors wish to thank all the participants who took the time to participate in this study.

\section{Authors' contributions}

$\mathrm{HN}$ and $\mathrm{CV}$ created the idea for the study and all authors were involved in developing and revising the questionnaire. CV collected the data and analysed the qualitative content. CC analysed statistical data. CV wrote the first draft of the manuscript and all authors participated in manuscript revision and approved the final version.

\section{Funding}

This study did not receive funding.

\section{Availability of data and materials}

The datasets used and/or analysed during the current study are available from the corresponding author on reasonable request. The data set generated during the study will not be shared in order to respect confidentiality and not to compromise research participant privacy.

\section{Declarations}

Ethics approval and consent to participate

The study received ethics approval from the Queen's University Belfast, School of Nursing and Midwifery Research and Ethics Committee (Ref: C.McVeigh.05.19.M1.V1)

Consent to participate in the study was obtained by completion and submission of the survey via the cloud-based platform.

\section{Consent for publication}

Non-Applicable.

\section{Competing interests}

The authors declare that they have no conflict of interest.

\section{Author details}

'School of Nursing and Midwifery, Queen's University Belfast, Belfast, UK. ${ }^{2}$ School of Medicine, Dentistry and Biomedical Sciences, Queen's University Belfast, Belfast, UK. ${ }^{3}$ Centre for Improving Health-Related Quality of Life, School of Psychology, Queen's University Belfast, Belfast, UK. ${ }^{4}$ McGill Meditation and Mind-Body Medicine Research Clinic (MMMM-RC) and 
Geri-PARTy Research Group, Jewish General Hospital, Montreal, Canada. ${ }^{5}$ Department of Psychiatry, McGill University, Montreal, Canada. ${ }^{6}$ Mindfulness UK, Taunton, Somerset, UK. ${ }^{7}$ School of Arts and Social Sciences, Department of Psychology, City University of London, London, UK.

\section{Received: 10 December 2020 Accepted: 8 December 2021} Published online: 20 December 2021

\section{References}

1. He FX, Turnbull B, Kirshbaum MN, Phillips B, Klainin-Yobas P. Assessing stress, protective factors and psychological well-being among undergraduate nursing students. Nurse Educ Today. 2018;68:4-12. https:// doi.org/10.1016/j.nedt.2018.05.013.

2. Kang YS, Choi SY, Ryu E. The effectiveness of a stress coping program based on mindfulness meditation on ISRN nursing 5 the stress, anxiety, and depression experienced by nursing students in Korea. Nurse Educ Today. 2009;29(5):538-43. https://doi.org/10.1016/j.nedt.2008.12.003.

3. Gibbons C, Dempster M, Moutray M. Stress, coping and satisfaction in nursing students. J Adv Nurs. 2011;67(3):621-32. https://doi.org/10.1111/j.13 65-2648.2010.05495.x.

4. Jimenez C, Navia-Osorio PM, Diaz CV. Stress and health in novice and experienced nursing students. J Adv Nurs. 2010;66(2):442-55. https://doi. org/10.1111/j.1365-2648.2009.05183.x.

5. Melincavage SM. Student nurses' experiences of anxiety in the clinical setting. Nurse Educ Today. 2011;31(8):785-9. https://doi.org/10.1016/j.nedt.2 011.05.007.

6. Chernomas WM, Shapiro C. Stress, depression, and anxiety among undergraduate nursing students. Int J Nurs Educ Scholarsh. 2013;10(1):25566. https://doi.org/10.1515/ijnes-2012-0032.

7. Halland E, De Vibe M, Solhaug I, Friborg O, Rosenvinge JH, Tyssen R, et al. Mindfulness training improves problem-focused coping in psychology and medical students: results from a randomized controlled trial. Coll Stud J. 2015:49(3):387-98

8. Noble H, Reid J, Walsh IK, Ellison SE, McVeigh C. Evaluating mindfulness training for medical and PhD nursing students. Br J Nurs. 2019;28(12):798802. https://doi.org/10.12968/bjon.2019.28.12.798.

9. Song $Y$, Lindquist R. Effects of mindfulness-based stress reduction on depression, anxiety, stress and mindfulness in Korean nursing students. Nurse Educ Today. 2015; 35(1):86-90. https://doi.org/10.1016/..nedt.2014.06.010.

10. Ratanasiripong $P$, Wang CCD. Psychological well-being of Thai nursing students. Nurse Educ Today. 2011;31(4):412-6. https://doi.org/10.1016/j. nedt.2010.08.002.

11. Oliver D. David Oliver: when "resilience" becomes a dirty word. Br Med J. 2017;358:190. https://doi.org/10.1136/bmj.j3604.

12. Kabat-Zinn J. Wherever you go, there you are: mindfulness meditation for everyday life. New York: Hyperion; 1994.

13. Richmond $K$, Zerbo $E$, Levounis $P$. What is mindfulness?. Becoming mindful: integrating mindfulness into your psychiatric practice. Arlington: American Psychiatric Association Publishing; 2016.

14. Siegel RD, Germer CK, Olendzki A. Mindfulness: what is it? Where did it come from?. Clinical handbook of mindfulness (pp. 17-35). New York: Springer; 2009. Mindfulness: What Is It? Where Did It Come From?

15. Sirgy MJ, Jackson PA. How to enhance the well-being of healthcare service providers and their patients? A mindfulness proposal Frontiers in Psychology. 2015;6:276. https://doi.org/10.3389/fpsyg.2015.00276.

16. Campillo E, Ricarte JJ, Ros L, Nieto M, Latorre JM. Effects of the visual and auditory components of a brief mindfulness intervention on mood state and on visual and auditory attention and memory task performance. Curr Psychol. 2018;37(1):357-65. https://doi.org/10.1007/s12144-016-9519-y.

17. Norris CJ, Creem D, Hendler R, Kober H. Brief mindfulness meditation improves attention in novices: evidence from ERPs and moderation by neuroticism. Front Hum Neurosci. 2018;12:315. https://doi.org/10.3389/ fnhum.2018.00315.

18. Chan RR, Giardino N, Larson JL. A pilot study: mindfulness meditation intervention in COPD. Int J Chronic Obstructive Pulm Dis. 2015;10:445. https://doi.org/10.2147/COPD.S73864.

19. Goyal M, Singh S, Sibinga EM, Gould NF, Rowland-Seymour A, Sharma R, et al. Meditation programs for psychological stress and well-being: a systematic review and meta-analysis. JAMA Intern Med. 2014;174(3):357-68. https://doi.org/10.1001/jamainternmed.2013.13018.
20. Goldhagen BE, Kingsolver K, Stinnett SS, Rosdahl JA. Stress and burnout in residents: impact of mindfulness-based resilience training. Adv Med Educ Pract. 2015;6:525-32. https://doi.org/10.2147/AMEP.S88580.

21. Pidgeon AM, Ford $L$, Klaassen F. Evaluating the effectiveness of enhancing resilience in human service professionals using a retreat-based mindfulness with Metta training program: a randomised control trial. Psychol Health Med. 2014;19(3):355-64. https:/doi.org/10.1080/13548506.2013.806815.

22. Epstein RM, Krasner MS. Physician resilience: what it means, why it matters, and how to promote it. Acad Med. 2013;88(3):301-3. https://doi.org/10.1 097/ACM.0b013e318280cffo.

23. Iqbal S, Gupta S, Venkatarao E. Stress, anxiety \& depression among medical undergraduate students \& their socio-demographic correlates. Indian J Med Res. 2015;141(3):354-7. https://doi.org/10.4103/0971-5916.156571.

24. Khamisa N, Peltzer K, Oldenburg B. Burnout in relation to specific contributing factors and health outcomes among nurses: a systematic review. Int J Environ Res Public Health. 2013;10(6):2214-40. https://doi.org/1 0.3390/ijerph10062214.

25. Dubale BW, Friedman LE, Denninger JW CZ, Mehta DH, Fricchione GL, et al. Systematic review of burnout among healthcare providers in sub-Saharan Africa. BMC Public Health. 2019;19:1247.

26. Mosadeghrad AM. Occupational stress and turnover intention: implications for nursing management. Int J Health Policy Manag. 2013;1(2):169-76. https://doi.org/10.15171/ijhpm.2013.30.

27. Labrague LJ, De Los Santos JAA, Falguera CC, Nwafor CE, Galabay JR, Rosales RA, et al. Predictors of nurses' turnover intention at one and five years' time. Int Nurs Rev. 2020;67(2):191-8. https://doi.org/10.1111/inr.12581.

28. van der Riet P, Rossiter R, Kirby D, Dluzewska T, Harmon C. Piloting a stress management and mindfulness program for undergraduate nursing students: student feedback and lessons learned. Nurse Educ Today. 2015; 35(1):44-9. https://doi.org/10.1016/j.nedt.2014.05.003.

29. Chen $Y$, Yang $X$, Wang $L$, Zhang $X$. A randomized controlled trial of the effects of brief mindfulness meditation on anxiety symptoms and systolic blood pressure in Chinese nursing students. Nurse Educ Today. 2013;33(10): 1166-72. https://doi.org/10.1016/j.nedt.2012.11.014.

30. Erogul $M$, Singer $G$, Mclntyre T, Stefanov DG. Abridged mindfulness intervention to support wellness in first-year medical students. Teach Learn Med. 2014;26(4):350-6. https://doi.org/10.1080/10401334.2014.945025.

31. Wylde CM, Mahrer NE, Meyer RM, Gold Jl. Mindfulness for novice pediatric nurses: smartphone application versus traditional intervention. J Pediatr Nurs. 2017;36:205-12. https://doi.org/10.1016/j.pedn.2017.06.008.

32. Spadaro KC, Hunker DF. Exploring the effects of an online asynchronous mindfulness meditation intervention with nursing students on stress, mood, and cognition: a descriptive study. Nurse Educ Today. 2016;39:163-9. https://doi.org/10.1016/j.nedt.2016.02.006.

33. Adler E, Clark R. An invitation to social research: how it's done. Cengage Learning: USA; 2014.

34. Corp IBM. IBM SPSS statistics for windows, version 24.0. IBM Corp: Armonk, NY; 2016.

35. King N, Horrocks C, Brooks J. Interviews in qualitative research. London: SAGE Publications Limited; 2018.

36. Mc Veigh C, Reid J, Carvalho P. Healthcare professionals' views of palliative care for American war veterans with non-malignant respiratory disease living in a rural area: a qualitative study. BMC palliative care. 2019;18(1):22. https://doi.org/10.1186/s12904-019-0408-7.

37. Said Z, Kheng GL. A review on mindfulness and nursing stress among nurses. Analitika. 2018;10(1):31-45. https:/doi.org/10.31289/analitika.v10i1.1589.

38. Yang E, Schamber E, Meyer R, Gold Jl. Happier healers: randomized controlled trial of Mobile mindfulness for stress management. J Altern Complement Med. 2018; 24(5):505-13. https://doi.org/10.1089/acm.2015.0301.

39. Karaca A, Şişman NY. Effects of a stress management training program with mindfulness-based stress reduction. J Nurs Educ. 2019:58(5):273-80. https:// doi.org/10.3928/01484834-20190422-05.

40. Ratanasiripong P, Park JF, Ratanasiripong N, Kathalae D. Stress and anxiety management in nursing students: biofeedback and mindfulness meditation. J Nurs Educ. 2015;54(9):520-4. https:/doi.org/10.3928/01484834-20150814-07.

41. Yüksel A, Yılmaz EB. The effects of group mindfulness-based cognitive therapy in nursing students: a quasi-experimental study. Nurse Educ Today. 2020;85:104268. https://doi.org/10.1016/j.nedt.2019.104268.

42. Marthiensen R, Sedgwick M, Crowder R. Effects of a brief mindfulness intervention on after-degree nursing student stress. J Nurs Educ. 2019;58(3): 165-8. https://doi.org/10.3928/01484834-20190221-07. 
43. Roulston A, Montgomery L, Campbell A, Davidson G. Exploring the impact of mindfulnesss on mental wellbeing, stress and resilience of undergraduate social work students. Soc Work Educ. 2018;37(2):157-72. https://doi.org/10.1 080/02615479.2017.1388776.

44. Aherne D, Farrant K, Hickey L, Hickey E, Mc Grath L, McGrath D. Mindfulness based stress reduction for medical students: optimising student satisfaction and engagement. BMC Med Educ. 2016;16(1):209. https://doi.org/10.1186/ s12909-016-0728-8.

45. O'Cathain A, Croot L, Duncan E, Rousseau N, Sworn K, Turner KM, et al.

Guidance on how to develop complex interventions to improve health and healthcare. BMJ Open. 2019;9(8):029954. https://doi.org/10.1136/bmjopen-2 019-029954.

\section{Publisher's Note}

Springer Nature remains neutral with regard to jurisdictional claims in published maps and institutional affiliations.

Ready to submit your research? Choose BMC and benefit from:

- fast, convenient online submission

- thorough peer review by experienced researchers in your field

- rapid publication on acceptance

- support for research data, including large and complex data types

- gold Open Access which fosters wider collaboration and increased citations

- maximum visibility for your research: over $100 \mathrm{M}$ website views per year

At BMC, research is always in progress.

Learn more biomedcentral.com/submissions 